\title{
Learning Disabilities Teachers' Attitudes About Professional Development to Address the Needs of Students with Gifted and Learning Disabilities (SGLD): A Qualitative Study
}

\author{
Yasir A Alsamiri ${ }^{1}$ \& Salman A Aljohni ${ }^{2}$ \\ ${ }^{1}$ Faculty of Education, University of Hail, Hail, Saudi Arabia \\ ${ }^{2}$ Ministry of education, Yanb, Saudi Arabia \\ Correspondence: Department of Special Education, Faculty of Education, University of Hail, Hail, Saudi Arabia. \\ E-mail: yasser1352@hotmail.com
}

Received: October 29, 2018 Accepted: December 6, 2018 Online Published: December 13, 2018

doi:10.5539/gjhs.v11n1p81 URL: https://doi.org/10.5539/gjhs.v11n1p81

\begin{abstract}
Learning disabilities teachers exercise a significant influence on the educational development of students with gifted and learning disabilities (SGLD). It is therefore important to understand their attitudes towards professional development in this area to effectively implement training and educational practices to address the needs of SGLD. The authors interviewed 8 learning disabilities teachers in Yanbu city in Saudi Arabia. The interviews were analysed using content analysis. Findings from the study suggest that further professional development in learning disabilities, giftedness and SGLD may assist in improving the educational outcomes of SGLD. The results of this study may assist teachers and educational personnel to seek the optimal methods to identify and assist SGLD.
\end{abstract}

Keywords: professional development, twice-exceptional, gifted students with learning disabilities, gifted, learning disabilitie

\section{Introduction}

This article explores the current intervention practices in primary schools in Saudi Arabia, on the importance of professional development for learning disabilities teachers in Students with Giftedness and Learning Disabilities (SGLD). The need for the professional development of learning disabilities primary school teachers is studied and presented in the relevant literature in several ways. However, at the core of such studies is the understanding that professional development is about the teachers' learning, in learning how to learn, and transforming their knowledge into practice for the benefit of the growth of SGLDs. A teacher's professional development is prevalent, with researchers considering it as central to the transformation of schools and crucial to school reform efforts (Garet, Porter, Desimone, Birman, \& Yoon, 2001). A surprising gap in the literature revealed that little research has described the knowledge and training needs of learning disabilities teachers regarding students with giftedness, students with learning disabilities and SGLDs (Park Academy, 2010; Montgomery, 2007).

Many definitions for giftedness can be found in the research literature (Beckmann \& Minnaert, 2018). The concept of giftedness has been much debated, depending on the scope of different research, the term is used in several ways (Mazzoli Smith \& Campbell, 2016; Miller, 2009). Early key studies by Terman (1916) provided a basic framework that concentrated on the intelligence concept and applied the intelligence quotient (IQ) score to help identify giftedness. Gagné (2011) developed the Differentiated Model of Giftedness and Talent (DMGT). He defined giftedness as, "the possession and use of outstanding natural abilities, called aptitudes, in at least one ability domain, to a degree that places a person at least among the top $10 \%$ of age peers" (p.11).

The concept of learning disabilities was first developed by Kirk and Bateman (1962), and referred to children with average intellectual ability or overhead, who moreover, demonstrated learning problems (Beckmann \& Minnaert, 2018). To date, the concept of learning disabilities continues to be hotly debated, particularly in how learning disabilities (LD) should be defined (Alqahtani, 2016; Alnaim, 2015). There is no consensus on the definition of LD, which may explain the elusiveness of LD terminology (Francis, Shywitz, Stuebing, Shywitz, Fletcher, 1996; Gilani, Roditi, \& Bhattacharyya, 2017; Manthorpe \& Martineau, 2013). The controversy around the definition of LD relates to the disabilities themselves. Because the term 'learning disabilities' refers to a variety of several types of learning difficulties, such as dyscalculia (impaired ability to learn age-appropriate 
math), dyslexia (impaired ability to learn to read) and dysgraphia (impaired ability to learn to write), makes it a concept that is challenging to define.

Moreover, while learning disabilities vary from person to person, someone with LD may have multiple learning disabilities (Alqahtani, 2016; Alnaim, 2015; Fletcher, Morris, \& Lyon, 2003 Firth, 2009). In Saudi Arabia, LD are defined as, "Disorders in one or more of the basic psychological processes involved in understanding or using spoken and written language which is manifested in disorders in listening, thinking, talking, reading, writing, spelling, or arithmetic and it is not due to factors related to mental retardation, visual or hearing impairments, or educational, social, and familial factors" (Ministry of Education of Saudi Arabia, 2002).

The concept of SGLD has been written about extensively, and while there have been few investigations, the concept has proven to be controversial (Lovett \& Sparks, 2011; Chimhenga, 2016; Gari, Mylonas, \& Portešová, 2015). Although there is a general understanding of what constitutes "giftedness" and "learning disability", there is little awareness that the two can sometimes be found in one student and can be considered mutually exclusive (Wormald, 2009; Mayes, 2016). These students are commonly referred to in the field as "twice-exceptional" (Foley-Nicpon, Allmon, Sieck, \& Stinson, 2011). Twice-exceptional students, or as this paper refers to them as SGLD, are students who exhibit superior intellectual ability and demonstrate a significant discrepancy in their level of achievement in a particular area of academic study, such as mathematics, reading, written expression or spelling. Their performance shows lower levels of what would be expected based on their general intellectual ability (Alkhunaini, 2013; Barber \& Mueller, 2011).

\section{Literature Review}

\subsection{Professional Development in Gifted Education}

Over the past few decades, research has identified the unique learning needs of gifted students (Henderson \& Jarvis, 2016; Jarvis \& Henderson, 2014). These needs can be met if appropriate programs are made available to students and if teachers are provided with opportunities for professional development (Benny \& Blonder, 2016; Kraut, Chandler, \& Hertenstein, 2016). According to several studies (e.g. Bangel, Moon, \& Capobianco, 2010; Sears, 2016; Murin, 2016), professional development is an ongoing process that includes, knowledge; education; learning and support activities aimed to promote teachers; skills and values changes in teaching to more effective education of gifted students; and a balance between individual, school and national needs. However, studies indicate that teachers with little or no professional development in teaching gifted students experience difficulties in meeting their students' needs, which can lead to feelings of resentment and inadequacy (Siegle \& Powell, 2004; Szymanski \& Shaff, 2013).

Several researchers have concluded that there are differences between teachers who receive professional development to meet gifted students' needs and those who do not (Alkhunaini, 2013; Shaunessy, 2007). For example, a study conducted by Hansen and Feldhusen (1994), wherein student questionnaires and observations of teachers in the classroom were used to assess the teaching skills and classroom environment of 82 teachers of gifted students, showed that trained teachers have higher teaching skills and can establish classroom environments that are more positive, compared to teachers without professional development. Therefore, it appears that the impact of professional development in giftedness results in an improvement in teachers' abilities to meet these students' needs.

Evidence from several empirical studies shows that professional development in giftedness, while teachers are in-service or in postgraduate studies, results in a greater understanding of giftedness and gifted education, thus enabling them to constantly reassess their own knowledge (e.g., Cashion \& Sullenger, 2000; Hansen \& Feldhusen, 1994). However, teachers who possess negative attitudes towards students with giftedness are less likely to be able to assist such students. These teachers often reinforce misconceptions and myths about students with giftedness, such as the idea that these students do not require assistance. In addition, such teachers are unlikely to seek further understanding of giftedness (Bohner \& Wänke, 2002). Moreover, they are unlikely to undertake professional development in giftedness. Teachers' attitudes have been proven to be important, as they often express a desire for professional development in giftedness with the aim to better understandig their students and providing appropriate support (Alsamiri, 2018).

\subsection{Professional Development in Learning Disabilities}

Teachers' attitudes toward students with LD and special education are usually multidimensional and may vary according to the various types of learning disabilities, as well as according to the teachers' professional development on how to address these conditions (Chimhenga, 2016). Some teachers have noted that because teaching students with LD is a collaborative task, it is important for both head teachers as well as other teachers 
to undertake professional development (Gari et al., 2015). Kamala and Ramganesh (2013) found that learning disabilities often go undetected in primary schools, and undiagnosed students do not receive the necessary assistance. This problem was considered a consequence of a lack of professional development with regards to learning disabilities. Alsamiri (2018) identified an interesting gap in the professional development of teachers. They examined the pedagogy and approaches for the inclusion of students with learning disabilities in Hong Kong and found that teachers who participated in the study, reported a need for professional development to help implement the curriculum to allow students with LD to participate within an inclusive environment, and learn with their peers in the mainstream classroom. Facilitating and implementing an inclusive environment requires knowledge about classroom management, differentiated instruction and balancing the behavioural needs of students with learning disabilities; all of which can be attained through professional development.

Professional development provides teachers with the necessary skills and strategies to assist all students. The literature shows that professional development can be long, intermittent, or as required (Karagiorgi \& Symeou, 2007). In addition, the literature supports the idea that professional development can improve teachers' views on inclusion of LD (Avramidis \& Kalyva, 2007). Carroll, Forlin, and Jobling (2003) report that when professional development is provided, teachers are more likely to help students acquire the necessary skills to help them cope.

\subsection{Professional Development in SGLD}

The issue of the identification and support of SGLD is a complex one which requires input and cooperation from numerous stakeholders to consider a student's emotional and social, as well as physical and educational development; taking into account the students, their families, and the school communities. With recognition from the education systems of SGLD and their unique needs, the aid of professional development for teachers, and the support from senior educational staff, SGLD are more likely to be provided with opportunities to reach their academic potential (Bianco \& Leech 2010; Wormald, 2009).

Bianco and Leech (2010) note that the research demonstrates that the lack of professional development in SGLD is the main obstacle to identifying and nominating SGLD for support programmes. Yet, these same teachers are expected to identify SGLD and make the necessary referrals through various screening methods (e.g., observation). This issue is only further aggravated by the general difficulty in identifying SGLD from the general population, especially if they were randomly included in standardised tests (Finger \& Palmer, 2001). Furthermore, like learning disability teachers, mainstream classroom education teachers have not received adequate professional development in the attributes of SGLD (Shaunessy, 2007). This is a dire situation, as the number of classroom teachers who possess the skills in identifying the characteristics of gifted students - let alone SGLD is very small (Park Academy, 2010).

An issue that needs addressing is the dichotomy of SGLD, namely the strengths and weaknesses inherent in identifying and supporting SGLD, as well as the appropriate professional development required for teachers in helping them develop the necessary skills to assist such students. Therefore, professional development needs to facilitate the social and academic achievement of SGLD (Alsamiri, 2018). According to Wormald (2009), it is important that teachers of gifted students and students with LD unite to better identify SGLD and provide appropriate educational programming. However, Ferrara's study of first- and third-year pre-service teachers found little difference in their attitudes towards SGLD.

In Australia, Wormald (2011) conducted a mixed methods study to investigate teachers' knowledge of SGLD. Responses indicated that only one subject in gifted education had been studied at the undergraduate level by $9.2 \%$ of teachers. This is in direct contrast to an undergraduate study in LD, where $20.6 \%$ of teachers had studied one subject with learning disabilities. Two teachers had undertaken a course on gifted students, and one teacher a course on learning disabilities in their Master of Special Education degree. Most teachers, including those from selective high schools, had no formal training in either gifted education or learning disabilities. The literature on SGLD reveals that professional development in SGLD is necessary to meet the needs of these students. However, professional development in this area remains limited, with teachers demonstrating more understanding about learning disabilities, followed by limited understanding about giftedness, and very limited to no understanding of SGLD.

\section{Research Design}

The authors employed a qualitative research design to gain an in-depth understanding of teachers' attitudes about the importance of professional development to address the needs of SGLD. Fifteen participants were selected and all were interviewed. The interview questions were based on a critical review of literature focused on the teachers' attitudes about the importance of professional development. The interview questions were derived from 
similar studies in the literature in this field. These questions were grouped into the following three categories and served to guide the interview process: the backgrounds of teachers, which included demographic questions; the importance of professional development in gifted as well as learning disabilities, which included eight questions; and the importance of professional development in SGLD, which included eight questions concerning teachers' perspectives on the support available for students with giftedness and learning disabilities, including their perspectives about the type of training or professional development necessary to help these students.

\subsection{Research Questions}

This study aims to examine Saudi primary learning disabilities teachers' attitudes towards the importance of professional development to address the needs of Students with Giftedness and Learning Disabilities (SGLD). The following research questions inform this study:

1) Why do teachers need professional development in giftedness to support students with gifted and learning disabilities?

2) Why do teachers need professional development in learning disabilities to support students with gifted and learning disabilities?

3) Why do teachers need professional development in SGLD to support students with gifted and learning disabilities?

\subsection{Procedure}

Specify the research design in the Method section. Were subjects placed into conditions that were manipulated, or were they observed naturalistically? If multiple conditions were created, how were participants assigned to conditions, through random assignment or some other selection mechanism? Was the study conducted as a between-subjects or a within-subject design?

\subsection{Participants}

The average age of the participating teachers was 27 years, ranging from 23 to 35 . The participating teachers had an average of 8 years of teaching experience, and the majority held a Bachelor's degree (8), followed by a postgraduate diploma (1). None had received any training or professional development in SGLD.

\subsection{Data Analysis}

An inductive content analysis (Elo \& Kyng"as, 2008) was conducted in this study and involved several steps. An inductive content analysis relies upon a coding unit consisting of words, sentences, or paragraphs that contain elements, 'related to each other through their content and context' (Graneheim \& Lundman, 2004, p. 106). The authors listened to all audio-recorded interviews, reviewed them, transcribed them into Arabic to confirm the accuracy of the transcripts, and corrected a few inconsistencies. Following the data analysis, the interviews were translated into English.

To ensure validity, the authosr forwarded two interview transcripts for independent data coding to the second author, the co-coder. The first author independently coded one interview, and the co-coder coded the same interview transcript. The frsit author and the co-coder compared the results of their coding and discussed any differences. Once an agreement was reached, the authors conducted open coding of the remaining interviews, reading them line-by-line and identifying initial codes.

The authors then checked the results of the open coding for accuracy of coding, carefully reading the results. The authors then read the open coding several times, and as many headings as necessary were written in the margins to describe all aspects of the content (Hsieh \& Shannon, 2005), Graneheim and Lundman (2004). The authors then refined and clustered the emerging codes and categories into themes (Hodgetts, Nicholas, \& Zwaigenbaum, 2013, p.168). The evidence for an established theme was arrived at by the triangulation of codes, frequency of occurrences, and interview quotes (Hodgetts et al., 2013, p.168). The authors reviewed all themes for reliability; these were then reassessed and confirmed by the co-coder (Patel \& Rose, 2014). The involvement of both authors and co-coder during each stage of the data analysis allowed for triangulation and peer checking (Brantlinger, Jimenez, Klinger, Pugach, \& Richardson, 2005).

\section{Result}

The following three key themes among the participants were identified by the authors: the need for professional development in giftedness, the need for professional development in learning disabilities, and the need for professional development in SGLD. 


\subsection{The Need for Professional Development in Giftedness}

The main issue raised by participants was that they are not adequately equipped to identify SGLD because none have undertaken any professional development or training in giftedness. Referral to gifted programs is based on identifying a child as gifted in the first instance. However, this may not be possible if the teacher does not know what to look for, particularly if a student has learning disabilities. The urgency for training in giftedness is evident in the following response from one teacher:

I told the principal that I need some training in giftedness because some students who have a learning disability also present as very intelligent but they don't achieve academically. It is important to address the needs of all students so I asked the principal to request that the Ministry of Education provide us with some courses that will enable us to help these students (T3).

While participants indicated that identifying students as gifted is problematic without having had the training, they also noted the lack of opportunities for professional development in giftedness offered by their schools:

I believe that training in gifted education will help teachers identify and support SGLD but unfortunately, there is no professional development offered to teachers in giftedness (T1).

I had no training to rely on for referring or identifying gifted students so I hope to have some professional development in giftedness (T6).

Several participants suggested that as learning disabilities teachers, they were not trained on identifying giftedness, much less SGLD, which is a cohort with which some of the teachers in this study had little to no experience. Their pre-service training focused primarily on learning disabilities. Moreover, while all schools provide support for students with learning disabilities, few provide support for students with giftedness. Therefore, most teachers feel they would not be able to refer students, even if they could identify them. The following comment expresses some of the problems related to identifying giftedness and referring such students:

I am sure most learning disability teachers do not understand the process for referring students to the gifted program or how the identification process works for students who are gifted (T8).

As a learning disabilities teacher, professional development should be offered to teachers to assist them to identify gifted students because the undergraduate degree does not provide enough information about students who are gifted. So, I think that training in giftedness is very important for learning disability teachers (T7).

The urgency for training in giftedness for learning disability teachers is demonstrated in the responses above, which suggest that learning disability teachers are not very well equipped to meet the needs of gifted students or $S G L D$. What is necessary, as shown in the comments, is the urgent necessity of more resources allocated to schools such as teachers in giftedness or resources to meet the needs of these students as well as those with $S G L D(T 4)$.

\subsection{The Need for Professional Development in Learning Disabilities}

Another key theme that emerged is the need for continued professional development for learning disability teachers. Ongoing professional development can help teachers stay abreast of the latest developments in the field, including new and refined methods of identification, as well as improved support strategies. All teachers participating in this study expressed that professional development could enhance their ability to assist their students. For example, one teacher noted the importance of experience, but also emphasised the need for professional knowledge about identification and support for learning disabled students, which can only be attained through professional development:

Experience is very important for teachers to identify students with learning disabilities because I can help them, but I do not know the latest methods of identification or support. Are there new methods of identifying and supporting learning disabled students? Professional development in learning disabilities is very important for teachers to enable them to identify and support these students (T5).

This sentiment is echoed in other participants' responses, who indicate that specialization in the field of learning disabilities is not always sufficient without ongoing professional development. This is important because teachers may learn about SGLD during their professional development. At the very least, they may become aware of the existence of such students. The following comments indicate that pre-service training is inadequate if teachers and in-service training is required for Saudi teachers:

I completed an undergraduate degree in teaching specialising in learning disabilities. But that is not enough and I am not aware of any new developments in the field of learning disabilities (T1). 
I've done an undergraduate degree in learning disabilities, and I am working with students with learning disabilities. However, I didn't know about SGLD because there is no professional development in learning disabilities. I'd never come across the term SGLD during pre-service training, so professional development would be useful to assist me to learn about these students (T4).

The need for professional development, undertaken both in Saudi Arabia and overseas, was cited by most learning disability teachers as important in continuing to provide their students with the highest quality assistance. However, opportunities for postgraduate study in learning disabilities are scarce and expensive, and therefore, out of reach for most teachers participating in this study. One teacher's view captures the general sentiment of most of the other participating teachers:

There are very few universities that provide postgraduate studies in learning disabilities. If I want to undertake such study, I have to pay for it myself, which is very expensive. In Saudi Arabia, only undergraduate degrees are free. I hope that the Ministry of Education will provide teachers with the opportunity to study about learning disabilities at a postgraduate level, both in Saudi Arabia and overseas (T8).

In summary, the need for professional development in giftedness and learning disabilities was noted by most teachers. Most expressed a desire for professional development to address the changing and varied needs of their students. Notwithstanding their desire to undertake further development, many teachers cannot afford the training; not to mention the limited opportunities for it within Saudi Arabia. Most claim that such opportunities should be made available by the Ministry of Education.

\subsection{The Need for Professional Development in SGLD}

All teachers expressed a desire for professional development in SGLD. None of the teachers in this study had received any training in SGLD, as the comments below indicate:

There is no training for teachers to help SGLD because in my primary school we only provide training in support for students with learning disabilities (T3).

I was not given any training on SGLD. I hope to have training that helps me deal with gifted or SGLD. The Ministry of Education has never provided professional development or training for learning disabilities teachers either (T6).

Teachers cited professional development in SGLD as necessary to help them identify and support such students. Many teachers expressed the view that professional development in SGLD should be conducted overseas since none of them had heard about this cohort of students in either pre-service or in-service teaching:

I need training in identifying the characteristics of SGLD because there is no training for learning disability teachers to help SGLD. The Ministry of Education provides very few training opportunities for learning disability teachers to identify and support students. For example, the ministry provided a very short workshop, which did not even mention SGLD (T3).

When I was in pre-service, I did not receive training or sufficient information that would help me identify or support SGLD. I have only ever heard about or undertook learning disabilities training (T8).

I think in-service training, specifically in $S G L D$, is probably more important than pre-service training because then I would be more familiar with both the learning disabilities and giftedness of these students (T2).

I would like the Ministry of Education to provide opportunities for training and professional development in $S G L D$ for teachers. This training and development should be in overseas universities because we need to know more about this area and we don't know very much at all about it in Saudi Arabia. (T7).

Teachers also claimed that teaching experience would not be enough to identify and support SGLD. They maintained that to identify and support these students, professional development, specifically in SGLD, is necessary. One teacher expressed this view for most:

I have been a learning disabilities teacher for five years, but during my teaching experience, I have not attended any workshops in learning disabilities. I do not know what is new in the field. In service training is not enough to identify and support SGLD and neither is experience as a learning disability teacher (T6).

To summarise, the data indicate that no teachers had undertaken any professional development in SGLD. The need for such training and professional development, both in Saudi Arabia and overseas, was cited as important to help identify and support this cohort of students. However, such professional development must be viewed as necessary by the Ministry of Education, according to teachers, who all claimed that opportunities for further study in training and development for learning disabilities, giftedness, and most importantly SGLD, is few and 
costly.

\section{Discussion}

This initial exploration of teachers' perspectives regarding the need for professional development in SGLD, suggests some possible solutions to the complex issue within schools in Saudi Arabia. A consistent factor which emerged in the three key themes is the need for professional development for teachers across the following areas of learning: giftedness, learning disabilities and SGLD. Notably, very few teachers had undertaken any professional development in giftedness and learning disability since becoming teachers. None had undertaken any professional development in SGLD, citing the lack of opportunity and cost as the primary reasons. This indicates that teachers are not necessarily aware of the latest developments in and strategies for teaching and learning students with learning disabilities or giftedness. Moreover, it is important to note that the lack of training in giftedness by learning disabilities teachers means they are unaware of the existence of SGLD and therefore, are unable to identify the characteristics of such students and make the appropriate referrals. The reason for this is because in eh literature, SGLD is usually discussed in terms of giftedness (Alkhunaini, 2013; Beckmann \& Minnaert, 2018). Despite some teachers claiming to have observed students who exhibit both giftedness and learning disabilities within their classrooms, the emphasis in the Saudi education system is placed on a deficit model; as demonstrated in this study, teachers generally focus on learning disabilities and solely address these.

Additionally, the results indicate that despite the ability of teachers to observe both giftedness and learning disabilities in their students, none of them could attribute this phenomenon to SGLD because they were unaware of such a cohort of students. This is not an unusual, as other studies indicate similar results (Gari et al., 2015), wherein SGLD in Greece constitute a group that is entirely neglected and only identified as having learning disabilities. Like the participants in the study conducted by Gari et al. (2015), Saudi teachers are able to understand some of the characteristics of SGLD, but have difficulty comprehending where the balance lies between giftedness and learning disabilities.

These results seem to reflect other studies in the literature which demonstrate that training and professional development in giftedness, as well as SGLD, is limited (Henley, Milligan, McBride, Neal, Nichols, \& Singleton, 2010). Troxclair (2013) argues that the ability of teachers in addressing SGLD needs will be detrimentally affected if they do not receive training or professional development in giftedness. According to Levi, Einav, Raskind, Ziv, and Margalit (2013), as well as Alsamiri. (2018), teachers who undertake professional development are more likely to understand students with giftedness and learning disabilities, and meet their needs. In this study, most teachers had received no professional development in either giftedness or SGLD.

The most important result which emerged from the themes in this study is the urgent need for professional development. If this study is representative of how little Saudi teachers know about SGLD, it suggests that there are many SGLD being neglected, or at the very least, underserved by the current education system and its focus on learning disabilities (Gari et al., 2015; Alkhunaini, 2013). The implications of the lack of professional development, particularly in giftedness and SGLD, are that learning disabilities teachers will be unable to address the unique and complex needs of these students. Consequently, SGLD are unlikely to achieve their full potential, especially in their area of giftedness, which remains unidentified.

According to the participants, results also indicate that responsibility for professional development should fall to the Saudi Ministry of Education. Moreover, if professional development is to be made available, it should come at no cost, or at the very least, be affordable. The results in this study indicate that despite the expressed desire of Saudi teachers to avail of professional development programs to better assist their students, the lack of available resources to them has proven frustrating. In relation to SGLD, a desire for professional development undertaken overseas was cited as important. This may be due to the scarcity of knowledge and possibilities for professional development in giftedness and SGLD in Saudi Arabia.

Additionally, the results indicate that the teachers' responses to the interview questions seem to be compatible with the educational needs of SGLD. For example, most teachers indicated that the educational needs of SGLD require the implementation of specifically tailored programs, including enrichment strategies and differentiated instruction for both learning disabilities and giftedness (Alsamiri, 2018). To provide this, a faculty who are aware of the needs of SGLD and the resources to effectively teach them, is required. The results in this study indicate that this is not currently the case in Saudi Arabia; however, teachers wish for such professional development (Alkhunaini, 2013; Alamer, 2017).

This study demonstrates the need for evidence-based practice when it comes to identifying and supporting SGLD. 
This can only be made possible if teachers undertake professional development. For this type of professional development to be made available to learning disability teachers, the acknowledgement of SGLD as a unique and specific cohort of students is required by the Ministry of Education, followed by the necessary implementation of policy, programs and resources within all schools.

The limitations of this study include the type of teachers who participated; only learning disability teachers were interviewed. Results may have possibly differed if teachers of giftedness or mainstream teachers were included in the study. Another limitation is context, which was restricted to one area (Yanba) and may not be indicative of results in rural or regional areas. Gender is another limitation; as only male teachers were interviewed; thus a more gender-balanced sample may be necessary in future studies. A possible limitation is that this study only focused on public primary schools, omitting private schools. The inclusion of private primary school teachers in future studies may produce different results, as teachers in the private sector are provided with more opportunities for professional development. Moreover, the private sector has more resources to meet the needs of both learning disabilities students, as well as those with giftedness.

\section{Conclusion}

In this paper, the results of the qualitative content analysis of eight primary learning disabilities teacher interviews are presented. The results demonstrate the urgent need for learning disabilities teachers to undertake professional development in SGLD. It is imperative for the Ministry of Education to formulate policies which acknowledge this cohort of students, and provide professional development opportunities for learning disabilities teachers in this area. In the absence or limited offering of professional development with regards to SGLD in Saudi Arabia, it is recommended that the Ministry of Education provides teachers with the opportunity to undertake professional development overseas, where much of the research in this field is conducted.

Without professional development, it is unlikely that learning disabilities teachers can meet the complex and unique requirements of this cohort of students. Consequently, SGLD will not achieve their full potential, and their giftedness will remain unidentified and thus, un-nurtured. As identifying learning disabilities in the gifted student population can be difficult, the role of learning disabilities teachers' knowledge and understanding is crucial in supporting and referring these students. Therefore, a recommendation is that learning disabilities teachers receive professional development, which will allow them to support SGLD and provide them with appropriately differentiated curricula or instruction, as well as other strategies and programs, specifically tailored for them.

\section{Competing Interests Statement}

The authors declare that there are no competing or potential conflicts of interest.

\section{Referencess}

Alamer, H. A. (2017). Exploring the experiences and insights of a twice-exceptional student finishing a college teacher preparation program: A case study (Unpublished doctoral dissertation). University of Northern Colorado.

Alkhunaini, N. A. (2013). Twice-exceptional learners: Saudi teachers' awareness and referral of gifted students with disabilities (Unpublished master's thesis). School of Education, University of Elon, Elon, United States.

Alnaim, F. (2015). Learning disabilities concept and identification: Primary teachers' perspectives in Saudi Arabia. International Journal of Social Science and Humanity, 5(12), 1040. https://doi.org/10.7763/IJSSH.2015.V5.601

Alqahtani, F. (2016). School-related stress and coping process of primary school girls with learning disabilities in Saudi Arabia (Doctoral dissertation, Queensland University of Technology).

Avramidis, E., \& Kalyva, E. (2007). The influence of teaching experience and professional development on Greek teachers' attitudes towards inclusion. European Journal of Special Needs Education, 22(4), 367-389. https://doi.org/10.1080/08856250701649989

Bangel, N. J., Moon, S. M., \& Capobianco, B. M. (2010). Preservice teachers' perceptions and experiences in a gifted education training model. Gifted Child Quarterly, 54(3), 209-221. https://doi.org/10.1177/0016986210369257

Barber, C., \& Mueller, C. T. (2011). Social and self-perceptions of adolescents identified as gifted, learning

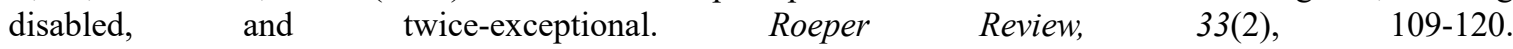
https://doi.org/10.1080/02783193.2011.554158 
Beckmann, E., \& Minnaert, A. (2018). Noncognitive characteristics of gifted students with learning disabilities: An in-depth systematic review. Frontiers in psychology, 9, 504. https://doi.org/10.3389/fpsyg.2018.00504

Benny, N., \& Blonder, R. (2016). Factors that promote/inhibit teaching gifted students in a regular class: results from a professional development program for chemistry teachers. Education Research International, 2016, (3), 1-11. https://doi.org/10.1155/2016/2742905

Bianco, M., \& Leech, N., (2010). Twice-exceptional learners: Effects of teacher preparation and disability labels on gifted referrals. Teacher Education Division of the Council for Exceptional Children, 33(4), 319-334. https://doi.org/10.1177/0888406409356392

Brantlinger, E., Jimenez, R., Klingner, J., Pugach, M., \& Richardson, V. (2005). Qualitative studies in special education. Exceptional children, 71(2), 195-207. https://doi.org/10.1177/001440290507100205

Carroll, A., Forlin, C., \& Jobling, A. (2003). The impact of teacher training in special education on the attitudes of Australian preservice general educators towards people with disabilities. Teacher Education Quarterly, 30(3), 65-79.

Cashion, M., \& Sullenger, K. (2000). "Contact us next year": Tracing teachers' use of gifted practices. Roeper Review, 23(1), 18-21. https://doi.org/10.1080/02783190009554056

Chimhenga, S. (2016). The challenges of intervention practices for gifted children with learning disabilities in primary schools of Zimbabwe. Global Journal of Advanced Research, 3(8), 764-770.

Elo, S., \& Kyngäs, H. (2008). The qualitative content analysis process. Journal of Advanced Nursing, 62, 107-115. https://doi.org/10.1111/j.1365-2648.2007.04569.x

Finger, S., \& Palmer, E. (2001). Child and adolescent mental health: A journal for all professionals working with children and young people. Association for Child and Adolescent Mental Health, 6(2), 50-100.

Firth, N. (2009). How do adolescents cope with learning disabilities? Australian Journal of Dyslexia and Other Learning Disabilities, 4, 23-29.

Fletcher, J. M., Morris, R. D., \& Lyon, G. R. (2003). Classification and definition of learning disabilities: An integrative perspective. Handbook of learning disabilities, 1, 30-56.

Foley-Nicpon, M., Allmon, A., Sieck, B., \& Stinson, R. D. (2011). Empirical investigation of twice-exceptionality: Where have we been and where are we going? Gifted Child Quarterly, 55(1), 3-17. https://doi.org/10.1177/0016986210382575

Francis, D. J., Shaywitz, S. E., Stuebing, K. K., Shaywitz, B. A., \& Fletcher, J. M. (1996). Developmental lag versus deficit models of reading disability: A longitudinal, individual growth curves analysis. Journal of Educational Psychology, 88(1), 3-1. https://doi.org/10.1037/0022-0663.88.1.3

Gagné, F. (2011). Academic talent development and the equity issue in gifted education. Talent Development \& Excellence, 3(1), 3-22.

Garet, M. S., Porter, A. C., Desimone, L., Birman, B. F., \& Yoon, K. S. (2001). What makes professional development effective? Results from a national sample of teachers. American educational research journal, 38(4), 915-945. https://doi.org/10.3102/00028312038004915

Gari, A., Mylonas, K., \& Portešová, S. (2015). An analysis of attitudes towards the gifted students with learning difficulties using two samples of Greek and Czech primary school teachers. Gifted Education International, 31(3), 271-286. https://doi.org/10.1177/0261429413511887

Gilani, S., Roditi, R., \& Bhattacharyya, N. (2017). Grade repetition and parents' perception of hearing loss: An analysis of data from children in the United States. The Laryngoscope, 127(3), 741-745. https://doi.org/10.1002/lary.26131

Graneheim, U. H., \& Lundman, B. (2004). Qualitative content analysis in nursing research: Concepts, procedures and measures to achieve trustworthiness. Nurse Education Today, 24, 105-112. https://doi.org/10.1016/j.nedt.2003.10.001

Hansen, J. B., \& Feldhusen, J. F. (1994). Comparison of trained and untrained teachers of gifted students. Gifted Child Quarterly, 38(3), 115-121. https://doi.org/10.1177/001698629403800304

Henderson, L., \& Jarvis, J. (2016). The gifted dimension of the Australian professional standards for teachers: Implications for professional learning. Australian Journal of Teacher Education (Online), 41(8), 60-83. https://doi.org/10.14221/ajte.2016v41n8.4 
Henley, J., Milligan, J., McBride, J., Neal, G., Nichols, J., \& Singleton, J. (2010). Outsiders Looking In? Ensuring that Teachers of the Gifted and Talented Education and Teachers of Students with Disabililties are Part of the'In-Crowd'. Journal of Instructional Psychology, 37(3). 203-209.

Hodgetts, S., Nicholas, D., \& Zwaigenbaum, L. (2013). Home sweet home? Families' experiences with aggression in children with autism spectrum disorders. Focus on Autism and Other Developmental Disabilities, 28, 166-174. https://doi.org/10.1177/1088357612472932

Hsieh, H.-F., \& Shannon, S. (2005). Three approaches to qualitative content analysis. Qualitative Health Research, 15, 1277-1288. https://doi.org/10.1177/1049732305276687

Jarvis, J. M., \& Henderson, L. C. (2014). Defining a coordinated approach to gifted education. Australasian Journal of Gifted Education, 23(1), 5-14.

Kamala, R., \& Ramganesh, E. (2013). Knowledge of specific learning disabilities among teacher educators in Puducherry, Union Territory in India. International Review of Social Sciences and Humanities, 6(1), 168-175.

Karagiorgi, Y., \& Symeou, L. (2007). Teachers' in-service training needs in Cyprus. European journal of teacher education, 30(2), 175-194. https://doi.org/10.1080/02619760701275487

Kraut, R., Chandler, T., \& Hertenstein, K. (2016). The interplay of teacher training, access to resources, years of experience and professional development in tertiary ESL reading teachers' perceived self-Efficacy. Gist: Education and Learning Research Journal, (12), 132-151. https://doi.org/10.26817/16925777.248

Lovett, B. J., \& Sparks, R. L. (2011). The identification and performance of gifted students with learning disability diagnoses: A quantitative synthesis. Journal of Learning Disabilities, 46(4), 304-316. https://doi.org/10.1177/0022219411421810

Manthorpe, J., \& Martineau, S. (2013). What can and cannot be learned from serious case reviews of the care and treatment of adults with learning disabilities in England? Messages for social workers. British Journal of Social Work, 45(1), 331-348. https://doi.org/10.1093/bjsw/bct142

Mayes, R. D. (2016). Educators' perceptions of twice exceptional African American males. Journal of African American Males in Education, 7(1), 20-34.

Mazzoli Smith, L., \& Campbell, R. J. (2016). So-called giftedness and teacher education: issues of equity and inclusion. Teachers and Teaching, 22(2), 255-267. https://doi.org/10.1080/13540602.2015.1055448

Miller, E. M. (2009). The effect of training in gifted education on elementary classroom teachers' theory-based reasoning about the concept of giftedness. Journal for the Education of the Gifted, 33(1), 65-105. https://doi.org/10.1177/016235320903300104

Ministry of Education of Saudi Arabia. (2002). Regulations of special education programs andInstitutes of Saudi Arabia. Retrieved from Ministry of Education website: http://www.se.gov.sa/rules/se_rules/index.htm

Montgomery, J. K. (2007). Characteristics and development of male adolescent studentswho are gifted, gifted twice-exceptional, or attention deficit: A mixed-methods study. (Doctoral Dissertation). Retrieved from Proquest Dissertations \& Theses database.

Murin, T. M. (2016). Administrator Perceptions Regarding Pennsylvania's MTSS/RtII Framework and Gifted Elementary Students (Doctoral dissertation, Insian University of Pennsylvania).

Park Academy, (2010). Park Academy, the discovery of intellectual giftedness. Retrieved from http://www.parkacademy.org/

Patel, M., \& Rose, J. (2014). Students' attitudes towards individuals with an intellectual disability. Journal of Intellectual Disabilities, 28(4), 90-103. https://doi.org/10.1177/1744629513511355

Sears, M. J. (2016). Experiences of Elementary Teachers Using Inclusion Models to Serve Gifted Students (Doctoral dissertation, Liberty University).

Shaunessy, E. (2007). Implications for gifted education. Gifted Child Quarterly, 51(2), 119-135. https://doi.org/10.1177/0016986207299470

Siegle, D., \& Powell, T. (2004). Exploring teacher biases when nominating students for gifted programs. Gifted Child Quarterly, 48(1), 21-29. https://doi.org/10.1177/001698620404800103

Speck, M., \& Knipe, C. (2001). Why can't we get it right? Professional development in our schools. Corwin Press, Inc., A Sage Publications Company. 
Szymanski, T., \& Shaff, T. (2013). Teacher perspectives regarding gifted diverse students. Gifted Children, 6(1), $1-27$.

Troxclair, D. A. (2013). Preservice teacher attitudes toward giftedness. Roeper Review, 35(1), 58-64. https://doi.org/10.1080/02783193.2013.740603

Wormald, C. (2009). An enigma: Barriers to the identification of gifted students with a learning disability (Unpublished doctoral thesis). School of Education, University of Wollongong, New South Wales, Australia.

\section{Copyrights}

Copyright for this article is retained by the author(s), with first publication rights granted to the journal.

This is an open-access article distributed under the terms and conditions of the Creative Commons Attribution license (http://creativecommons.org/licenses/by/4.0/). 